\title{
POSSÍVEIS DIÁLOGOS ENTRE ETNOMATEMÁTICA E MODELO DOS CAMPOS SEMÂNTICOS (MCS)
}

\author{
POSSIBLE DIALOGUES BETWEEN ETHNOMATHEMATICS AND THE SEMANTIC FIELDS MODEL \\ (SFM)
}

\section{Rodolfo Chaves, Weverton Augusto da Vitória, Ivonilton Pereira de Novais}

Instituto Federal do Espírito Santo

E-mail: rodolphochaves20@gmail.com, wevertonvitoria@gmail.com, ivoniltonnovais@gmail.com

\section{Resumo}

O presente trabalho é fruto de uma pesquisa bibliográfica, de abordagem qualitativa, que busca possíveis diálogos entre a Etnomatemática e o Modelo dos Campos Semânticos (MCS). Para tal tomamos oito premissas, das quais momentaneamente destacamos: (P2) - as concepções de Patrick Geddes (um aluno em contado com a realidade do seu ambiente desenvolve atitudes criativas em relação ao mesmo, cabendo aos professores desempenhar o papel de mediadores de uma educação que incorpore uma análise da realidade socioambiental opondo-se àquela em que o aluno é levado a ignorar as consequências dos seus atos); (P3) - Frente a diferentes realidades, distintos saberes de natureza matemática são produzidos; (P4) - A intervenção sociocultural de uma ação pedagógica não vinculada à realidade dos alunos possibilita um enfraquecimento da identidade cultural desses alunos e a torna frágil (a identidade) no que se refere à manutenção de seus valores; (P6) - As formas como se produz conhecimento são dependentes de diversas variáveis que compõem as dinâmicas de uma cultura, logo, não há como pensar em produção única que seja válida em todos os contextos a todos os indivíduos; (P7) - A Educação Matemática que defendemos produz legitimidade, dentro da escola, para os modos de produção de significado da rua (ato político, ato pedagógico). O objetivo geral do trabalho é discutir, analisar e apresentar possíveis relações dialógicas entre a Etnomatemática e o Modelo dos Campos Semânticos, tomados como suporte à formação de professores a partir de suas premissas. Tal objetivo nos leva à seguinte pergunta-diretriz: Que leituras plausíveis emergem da análise de estudos e discussões a respeito de possíveis relações dialógicas entre a Etnomatemática e o Modelo dos Campos Semânticos, tomados como suporte à formação de professores as premissas do trabalho? O objetivo específico apresentado é: Apresentar, discutir e analisar possibilidades de confluências entre a Etnomatemática e o MCS que possibilitem atacar o fracasso do Ensino Tradicional de Matemática (ETM).

Palavras-chave: Etnomatemática. Modelo dos Campos Semânticos (MCS). leitura plausível. produção de significado. Práticas Educativas Investigativas (PEI).

\section{Abstract}

This work is the result of a bibliographical research, qualitative approach that seeks possible dialogues between Ethnomathematics and the Model of Semantic Fields. To do this take eight premises, which briefly include: (P2) - the conceptions of Partick Geddes (a student in contact with the reality of their environment develops creative attitudes toward same, 
leaving the teachers play the role of executors of education incorporating an analysis of the socio-environmental reality opposing the one in which the student is taken to ignore the consequences of their actions); (P3) - Faced with different realities, different mathematical nature of knowledge are produced; (P4) - The socio-cultural intervention of a pedagogical action not linked to the reality of students enables a weakening of the cultural identity of these students and makes it brittle (identity) with regard to maintaining its values; (P6) - The ways in which knowledge is produced are dependent on several variables that make up the dynamics of a culture, so there is no way consider only production that is valid in all contexts to all individuals; (P7) - The mathematics education we advocate produces legitimacy within the school to the street meaning of modes of production (political act, pedagogical act). The overall objective is to discuss, analyze and present possible dialogical relations between the Ethnomatematics and the Model of Semantic Fields, taken as support to teacher training from their premises. This objective begs the question-guideline: Let plausible readings emerge from the analysis of studies and discussions about possible dialogical relations between the Ethnomatematics and the Model of Semantic Fields, taken as support for teacher training the premises of work? The specific objective is presented: Present, discuss and analyze possibilities confluences between Ethnomathematics and the MCS to enable attack the failure of Traditional Teaching Mathematics (ETM).

Keywords: Ethnomathematics. Model of Semantic Fields (MCS). plausible reading. production meaning. Investigative Educational Practices (PEI). 


\section{INTRODUÇÃO}

\subsection{O problema}

\subsubsection{A partir de olhares legitimados e chancelados pela academia}

É inegável que urge atingirmos de forma contundente o fracasso do ensino da Matemática e, portanto, fazer emergir os (e contrapormo-nos aos) dispositivos de controle de manutenção desse quadro. O tipo de ensino em questão é apresentado em Chaves (2004) como Ensino Tradicional de Matemática (ETM) onde é apontado que alguns desses dispositivos são fixados ao se apresentar a Matemática de forma excludente, meritocrática, promotora de uma educação aos moldes bancários, descontextualizada e descompromissada com o mundo em que o aluno vive. Ao agir assim, o professor exalta o mito positivista do especialista:

Aquele que possui a chancela de produzir verdades centradas na forma do discurso científico, balizadas por investigações mais rigorosas de uma parte do todo, sendo necessário para tal, fragmentar o saber em compartimentos hierarquicamente bem ordenados; isto é, o discurso científico é competente, por ser respaldado institucionalmente, portanto, autorizado e cabendo à teoria o papel de ser hierarquicamente superior à prática, por advir do campo das ideias (CHAVES, 2004, p.100).

No ETM é típico que os saberes cotidianos sejam negligenciados em detrimento aos saberes escolares. E ainda,

o conteúdo programático é o elemento central, principal e irrefutavelmente é colocado além do bem e do mal. A aula expositiva, nos moldes do ETM, é o lugar-comum da pregação enunciativa do expositivista ou de práticas educativas expositivistas; uma aula onde o professor - ser falante - ocupa grande parte do tempo envolvido com a exposição, e, o aluno - ser ouvinte - aceita passivamente as verdades apresentadas (CHAVES, 2004, p.79).

O ambiente de aprendizagem peculiar às práticas educativas expositivistas, caracterizadas pelo monólogo do professor - o ser falante (pergunta e responde a ele mesmo) - é 
"apresentado através de um discurso unilateral, do professor, com referências exclusivas à Matemática e onde uma programação curricular rígida se põe à frente do processo". (CHAVES, 2004, p.79). Nesta mesma obra é possível observar que no ETM os métodos de ensino hegemônicos (legitimados por aqueles que exercem o poder oficial e cartorial) não utilizam práticas voltadas à realidade, nem como ponto de chegada, nem como ponto de partida; muito menos como táticas seja à fixação ou à construção da aprendizagem, isso porque nas instituições escolares - instituições de sequestro para Chaves (2004) - atividades de tal envergadura são tidas como possíveis instrumentos de ruptura no exercício de controle e do "expositivismo professoral"1. Já educadores, quando as utilizam, o fazem tãosomente de maneira ilustrativa ou lúdica, como passatempo e não como procedimento de ensino ou uma possível tática de transformação da realidade a partir da aprendizagem. A prova cabal de tal afirmação pode ser vista nas Diretrizes curriculares Nacionais - DCN (BRASIL, 2013):

A escola tem tido dificuldades para tornar os conteúdos escolares interessantes pelo seu significado intrínseco. É necessário que o currículo seja planejado e desenvolvido de modo que os alunos possam sentir prazer na leitura de um livro, na identificação do jogo de sombra e luz de uma pintura, na beleza da paisagem, na preparação de um trabalho sobre a descoberta da luz elétrica, na pesquisa sobre os vestígios dos homens primitivos na América e de sentirem o estranhamento ante as expressões de injustiça social e de agressão ao meio ambiente (BRASIL, 2013, p.116).

Em outra trajetória, provavelmente devido à ausência de material que busque uma possível confluência, é possível se pensar que as preocupações pertinentes ao Modelo dos Campos Semânticos (MCS) e à Etnomatemática (como procedimento metodológico de ensino e também de pesquisa) são antagônicas ou não compartilhem um mesmo espaço comunicativo.

1 Termo cunhado por Chaves (2004, p.87) para designar um ambiente favorável à perpetuação do efeito Dolly ou clonagem acadêmica (perpetuação dos iguais) que é um instrumento tático que colabora para "a manutenção do ETM e, por conseguinte, com as formas de poder que se perpetuam na e a partir da escola". 
Pelo prisma da Etnomatemática é possível discutir não apenas a política de conhecimento dominante praticada na escola, bem como fazer emergir conhecimento não-hegemônico produzido por aqueles que não são chancelados pela academia (saberes populares) advindo de práticas sociais e confrontá-lo com a política de conhecimento dominante. Nessa direção é possível observar que as DCN apontam que

o conhecimento de valores, crenças, modos de vida de grupos sobre os quais os currículos se calaram durante uma centena de anos sob o manto da igualdade formal, propicia desenvolver empatia e respeito pelo outro, pelo que é diferente de nós, pelos alunos na sua diversidade étnica, regional, social, individual e grupal, e leva a conhecer as razões dos conflitos que se escondem por trás dos preconceitos e discriminações que alimentam as desigualdades sociais, étnico-raciais, de gênero e diversidade sexual, das pessoas com deficiência e outras, assim como os processos de dominação que têm, historicamente, reservado a poucos o direto de aprender, que é de todos (BRASIL, 2013, p.115).

O MCS foi desenvolvido por Romulo Campos Lins, a partir de 1986, vislumbrando a possibilidade de ir além da relação dicotômica de "acertar" ou "errar", pois seu propósito está vinculado a inquietações pertinentes a professores, sobretudo, os de Escola Básica, que tentam caracterizar e compreender aquilo que leva os alunos a "errarem", mas sem colocar o "erro" como um elemento para fins meritocráticos.

\subsubsection{A partir de olhares não-legitimados e não-chancelados: um trânsito rumo à chancela da academia}

Nossa experiência profissional em formação de professores (desenvolvida em algumas unidades federativas - SP, RJ, ES, MG e BA) transita por atividades, sobretudo de extensão, que tiveram início ainda no extinto Projeto Rondon (que era vinculado ao também extinto Ministério do Interior) nos idos dos anos de 1980, passando por Colégios de Aplicação, 
secretarias municipais de ensino, grupos de pesquisas em Educação Matemática e programas governamentais como o PIBID (Programa Institucional de Bolsas de Iniciação à Docência, CAPES) e o Multicurso Matemática ${ }^{2}$ - sempre pautados na tríade indissociável de ensino, pesquisa e extensão - envolvendo concomitantemente professores das redes de Ensino Básico e licenciandos, desenvolvendo trabalhos a partir de nossas respectivas práticas docentes, no campo da produção de Materiais Didático-pedagógicos (MDP), sobretudo jogos e materiais manipulativos dentre outros recursos didáticos, com o propósito e atingir e superar o fracasso do ensino da Matemática.

A dinâmica adotada que exibiremos a seguir denomina-se sistemática do conjunto de ações desenvolvidas pelo professor no ciclo de discussão em grupo, apresentada em Chaves (2000) e proposta aos processos de formação pré (inicial) e em serviço (continuada) de professores de Matemática.

A partir de 2001 especificamos o foco e nos voltamos às questões socioambientais, onde passamos a nos preocupar não apenas com possíveis aplicações da Matemática na Escola Básica, mas principalmente em como utilizá-la, a partir da realidade socioambiental do aluno, para efetuar leituras críticas e plausíveis do mundo. Nesse viés passamos então a trabalhar na égide da Etnomatemática, com finalidade de orientar e acenar à base nacional comum um possível currículo de Matemática, no viés da Pedagogia da Alternância, com monitores (professores) e alternantes (alunos) das Escolas Famílias Agrícolas de MG (CHAVES, 2005).

2 Programa de formação continuada (em serviço) dirigido a professores da rede pública estadual do ES, desenvolvido com tutores (Educadores matemáticos, professores do curso de Licenciatura em Matemática do Instituto Federal de Educação Tecnológica do ES - IFES), com a Fundação Roberto Marinho (FRM) e com a Secretaria Estadual de Educação (SEDU) no período de 2008 a 2010. A dinâmica desse programa foi pautada por encontros presenciais (na forma de seminários, oficinas e visitas técnicas), por reuniões quinzenais de grupos de estudo em escolas-sede (envolvendo somente professores da rede pública) e por acessos contínuos em ambiente virtual (AV) (com assistência de tutores e técnicos da FRM). Nos encontros presenciais são discutidos temas sugeridos por roteiros de estudos que abordam o conteúdo programático no viés de abordagens preciosas à Educação Matemática como Modelagem Matemática, Resolução de Problemas, Etnomatemática, História da Matemática e Jogos e Materiais Manipulativos. Nesta proposta de trabalho, na modalidade pôster, objetivamos mostrar os resultados do trabalho desenvolvido, como primeiro trabalho sistematizado e conjunto de extensão desenvolvido pelos docentes do recém-criado curso de Licenciatura em Matemática do IFES. 
Trabalhamos também com diversas disciplinas, principalmente na graduação, das quais destacamos especialmente duas (Matemática Aplicada às Ciências da Terra e da Natureza e Tendências de Pesquisa em Educação Matemática). Essas duas disciplinas, desde que começamos a ministrá-las (de 2009 em diante) têm nos impulsionado em direção ao desenvolvimento de estudos e pesquisas na área de Etnomatemática, da mesma forma que os trabalhos acadêmicos que orientamos, somados à nossa prática têm nos levado a trabalhar com o MCS.

Portanto, além do aporte teórico para o desenvolvimento deste trabalho, tomamos nossas práticas e discussões no Grupo de Estudos e Pesquisas em Matemática Pura, Matemática Aplicada e Educação Matemática (Gepemem) como referência.

\subsection{A proposta}

O que propomos neste trabalho é analisar se existe $(\mathrm{m})$ (quais as) possibilidade(s) de efetuar relação(ões) entre Etnomatemática e MCS com vistas a quebrar a inércia mantenedora do ETM. Para tal, neste texto, entenderemos saberes cotidianos como modos não-hegemônicos de matematizar, bem como dinâmicas matemáticas não-legitimadas pela academia e saberes escolares como modos hegemônicos de matematizar, bem como dinâmicas matemáticas legitimadas pela academia.

Assim, para o desenvolvimento desta pesquisa tomamos algumas premissas:

$\left(P_{1}\right)$ - No que se refere aos processos de formação de professores (inicial pré-serviço - e continuada - em serviço) é indispensável que se trabalhe indissociavelmente a partir da tríade ensino, pesquisa e extensão para nos contrapormos ao ETM.

$\left(P_{2}\right)$ - Que se tome como referência, modelo e código as concepções de Patrick Geddes ${ }^{3}$ de que "um aluno em contato com a realidade do seu

3 (1854-1923), biólogo e filósofo escocês, considerado o pai da Educação Ambiental, conhecido por seu pensamento inovador nos campos do planejamento urbano e da educação. 
ambiente desenvolve atitudes criativas em relação ao mesmo, cabendo aos professores desempenhar o papel de mediadores de uma educação que incorpore uma análise da realidade socioambiental opondo-se àquela em que o aluno é levado a ignorar as consequências dos seus atos" (CHAVES, 2004, p.81-82).

$\left(P_{3}\right)$ - Frente a diferentes realidades, distintos saberes de natureza matemática são produzidos;

$\left(\mathrm{P}_{4}\right)$ - $\mathrm{A}$ intervenção sociocultural de uma ação pedagógica não vinculada à realidade dos alunos possibilita um enfraquecimento da identidade cultural desses alunos e a torna frágil (a identidade) no que se refere à manutenção de seus valores.

$\left(P_{5}\right)$ - Quem produz significado não é o emissor, mas o receptor da enunciação e, portanto, a produção de significado se dá sempre no interior de atividades (LINS, 1999, p.88).

$\left(P_{6}\right)$ - As formas como se produz conhecimento são dependentes de diversas variáveis que compõem as dinâmicas de uma cultura, logo, não há como pensar em produção única que seja válida em todos os contextos a todos os indivíduos.

$\left(P_{7}\right)$ - A Educação Matemática que defendemos produz legitimidade, dentro da escola, para os modos de produção de significado da rua (ato político, ato pedagógico) (LINS, 1999, p.92),

$\left(P_{8}\right)$ - O desenvolvimento intelectual se origina na interiorização de formas produzidas socialmente (VYGOTSKY apud LINS, 1999, p.79).

As obras, Chaves (2005, p. 116-117 e 2004, p.160-185), chamam atenção para o fato de que, ao se tomar as premissa supracitadas, com o propósito de se contrapor ao ETM, há de se lutar para emergir a questão do laboro colaborativo de alunos e professores, sobretudo no desenvolvimento de ações que sejam transformadoras e, para tal, devemos trazer para o contexto escolar modos não-hegemônicos de matematizar, bem como dinâmicas matemáticas não-legitimadas pela academia para confrontarmos com modos hegemônicos de matematizar, bem como dinâmicas matemáticas legitimadas pela academia. 
As táticas desenvolvidas para atingir as premissas supracitadas (de $\left(P_{1}\right)$ a $\left(P_{8}\right)$ ) são ações sistematizadas que seguem a seguinte dinâmica, da qual neste texto denominamos de sistemática apresentada em Chaves (2000):

A sistemática do conjunto de ações desenvolvidas pelo professor no ciclo de discussão em grupo sobre um problema $\leftrightarrow$ planejamento de uma ação diferencial ${ }^{4}$ para atacar esse problema $\leftrightarrow$ aplicação conjunta (professor + monitor/licenciando + aluno) da ação diferencial planejada $\leftrightarrow$ discussão da ação realizada $\leftrightarrow$ replanejamento. (CHAVES, 2000, p.201).

Para tal, entendemos então que oportunizar ao docente a participação em atividades voltadas à realidade do aluno, com foco em questões socioambientais, é um ambiente fecundo à sua formação, bem como deveras salutar aos processos de ensino e de aprendizagem, sobretudo para futuros professores de Matemática que atuarão na Educação Básica. Romper com a inércia mantenedora do ETM, incentivando, orientando e trabalhando colaborativamente com o professor para que se desenvolva práticas educativas (e produza MDP), que envolvam dinâmicas matemáticas hegemônicas (aquelas chanceladas pela academia), ou não-hegemônicas (aquelas tomadas na prática que não necessariamente sejam chanceladas pela academia, que não sejam reconhecidas como um procedimento matemático convencional institucionalizado, conforme apresentado por Knijnik et al (2012, p.22-23)) possibilita a formação de ambientes de investigação, tomando a Matemática como ferramenta de leitura do mundo, conforme apresentado em Chaves (2004), com foco na interdisciplinaridade.

\section{PERCURSO METODOLÓGICO}

4 Ação que visa alcançar os objetivos estabelecidos em grupos de pesquisa-ação para produção de materiais didático-pedagógicos (MDP) ou que leve o grupo/indivíduo a desenvolver determinada tarefa ou a refletir a respeito de sua prática ou de um tema proposto. Tal ação é consequência de uma intervenção diferencial autorregulada. Na intervenção diferencial autorregulada (intervenção na realidade por diferenciação da ação esperada dos sujeitos) o professor intervém, em sala de aula, a partir de sua margem natural de liberdade, permanecendo como juiz de suas próprias ações, pois produz modificações neste ambiente à medida que as discute com os demais professores. (BALDINO; CARRERA DE SOUZA, 1997). 


\subsection{O problema}

No que tange à apresentação deste trabalho, segundo Gil (2010), deparamo-nos com uma pesquisa de abordagem qualitativa, cujo método empregado foi o bibliográfico, tomando como suporte Baldino \& Carrera de Souza (1997), Brasil (2013, 1998 e 1996), Chaves (2005, 2004 e 2000), Francisco (2015), Knijnik et al (2012), Knijnik (1996), Lins (2012 e 1999), Monteiro (2004) e Silva \& Lins (2013).

Após leitura analítica, na ótica de Gil (2010, p.45-64), cumpridas as etapas de leitura integral das obras, identificação das ideias-chaves, hierarquização e sistematização das ideias, passamos para etapa de leituras interpretativas advindas de Knijnik et al (2012), Chaves (2000, 2004 e 2005) e Lins (1993, 1999 e 2012). Os modos de produção de significado constituídos das leituras, análises, discussões e interações apontaremos a seguir, mas desde já, esclarecemos que esta pesquisa não está encerrada; ao contrário disso, ela constitui-se como um projeto "guarda-chuva" de onde saíram um Trabalho de Conclusão de Curso (TCC) desenvolvido junto ao Curso de Licenciatura em Matemática, Ifes, câmpus Vitória (LIMAT), um projeto de mestrado junto ao Programa de Pós-Graduação em Educação em Ciências e Matemática, Ifes, campus Vitória (EDUCIMAT) e um projeto de pós-doutorado junto ao Grupo de Estudos e Pesquisas em Educação Matemática - GEPEMat - no Programa de PósGraduação em Educação Matemática e Ensino de Ciências (PPGEMeEF), no Centro de Ciências Naturais e Exatas da Universidade Federal de Santa Maria, RS (CCNE/UFSM).

É usual que a Matemática como área de conhecimento, no contexto escolar, sobretudo na Educação Básica, mantenha um caráter meramente teórico. Em nossa prática docente, como formadores e acadêmicos, observamos que alunos e professores clamam por utilizarem a Matemática de forma prática, palpável, como "ferramenta de leitura do mundo" (CHAVES, 2004), para que possam, por exemplo, se apropriar da mesma em projetos pedagógicos, fato que dificilmente ocorre e, quando ocorre, restringe-se a leituras que redundam em análise superficiais e de baixíssima densidade epistêmica de gráficos de setor circular ou gráficos de barras. Tal cenário assim se configura principalmente porque em seu processo de formação, 
o professor tem acesso exclusivo a uma Matemática puramente teórica, onde se estuda a Matemática pela, por e para a Matemática em detrimento de possíveis aplicações.

O objetivo geral do trabalho é discutir, analisar e apresentar possíveis relações dialógicas entre a Etnomatemática e o MCS, tomados como suporte à formação de professores a partir de suas premissas (de $\left(P_{1}\right)$ a $\left.\left(P_{8}\right)\right)$. Tal objetivo nos leva à seguinte pergunta-diretriz: Que leituras plausíveis emergem da análise de estudos e discussões a respeito de possíveis relações dialógicas entre a Etnomatemática e o Modelo dos Campos Semânticos, tomados como suporte à formação de professores as premissas do trabalho $\left(\right.$ de $\left(P_{1}\right)$ a $\left.\left(P_{8}\right)\right)$ ?

O objetivo específico aqui suscitado é: Apresentar, discutir e analisar possibilidades de confluências entre a Etnomatemática e o MCS que possibilitem atacar o fracasso do Ensino Tradicional de Matemática (ETM).

\subsection{A proposta}

\subsubsection{A partir de olhares legitimados e chancelados pela academia}

Para caminharmos em busca às considerações apresentas nas premissas $\left(P_{2}\right)$ a $\left(P_{7}\right)$, Monteiro (2004) sugere confrontar articulações entre saberes escolares e cotidianos e, para tal, toma como referência os Parâmetros Curriculares Nacionais (PCN).

A ampla gama de conhecimentos construídos no ambiente escolar ganha sentido quando há interação contínua e permanente entre o saber escolar e os demais saberes, entre o que o aluno aprende na escola e o que ele traz para a escola (BRASIL, 1998, p.43).

Pela mesma trajetória, A Lei de Diretrizes e Bases da Educação Nacional (LDB), Lei no 9.394, de 20 de dezembro de 1996, em seu Artigo 26 contempla que os currículos da Educação Básica devem ter uma base comum, a ser complementada por uma parte diversificada, exigida pelas características regionais e locais da sociedade e em seu caput 10 garante que 
Os currículos a que se refere o caput devem abranger, obrigatoriamente, o estudo da língua portuguesa e da matemática, o conhecimento do mundo físico e natural e da realidade social e política, especialmente do Brasil (BRASIL, 1996).

Caminhando nesta direção, suscitando as premissas (de (P4) a (P8)), os PCN apontam para o fato de que:

A atividade matemática escolar não é "olhar para as coisas prontas e definitivas", mas a construção e a apropriação de conhecimento pelo aluno, que se servirá dele para compreender e transformar sua realidade;

No ensino da Matemática, destacam-se dois aspectos básicos: um consiste em relacionar observações do mundo real com representações (esquemas, tabelas, figuras, escritas numéricas); outro consiste em relacionar estas representações com princípios e conceitos matemáticos. Nesse processo, a comunicação tem grande importância e deve ser estimulada, levando-se o aluno a 'falar' e a 'escrever' sobre Matemática, a trabalhar com representações gráficas, desenhos, construções, a aprender como organizar e tratar dados;

O significado da Matemática para o aluno resulta das conexões que ele estabelece entre ela e as demais áreas, entre ela e os Temas Transversais, entre ela e o cotidiano e das conexões que ele estabelece entre os diferentes temas matemáticos;

A seleção e organização de conteúdos deve levar em conta sua relevância social e sua contribuição para o desenvolvimento intelectual do aluno e não deve ter como critério apenas a lógica interna da Matemática. (BRASIL 1998, p.56-57).

Dessa forma é legítimo que busquemos um solo epistemológico para combater as disparidades e distorções hora apontadas pelos PCN (BRASIL, 1998), DCN (BRASIL, 2013) e LDB (BRASIL, 1996). O solo que optamos por nos alicerçar, portanto, apresentamos a seguir. 


\subsubsection{Aportes epistemológicos - Etnomatemática}

Tomamos a Etnomatemática como procedimento metodológico de ensino por considerarmos que, a partir dela, é possível tanto referendarmos os elementos supracitados elencados nos PCN, quanto discutir não apenas as políticas de conhecimento dominante praticadas nas escolas, mas também trazer à tona conhecimento não-hegemônico produzido por aqueles que não são chancelados pela academia - saberes populares - advindos de práticas sociais e confrontá-los com a política de conhecimento dominante, produzindo assim, um viés com $\left(P_{2}\right),\left(P_{3}\right), \ldots,\left(P_{8}\right)$.

O pensamento etnomatemático está centralmente interessado em examinar as práticas de fora da escola, associadas a racionalidades que não são idênticas à racionalidade que impera na Matemática Escolar, com seus estreitos vínculos com a razão universal instaurada pelo lluminismo. Mas é preciso que se diga: olhar para essas outras racionalidades, sem jamais se esquecer do que está no horizonte, é pensar outras possibilidades para a Educação Matemática praticada na escola (KNIJNIK et al, 2012, p.18).

\subsubsection{Aportes epistemológicos - Modelo dos Campos Semânticos (MCS)}

Se por um lado tomar a Etnomatemática, como procedimento metodológico de ensino, nos faculta realizar as questões por hora apresentadas, é a partir do MCS que vislumbramos a possibilidade de ir além da relação dicotômica de "acertar" ou "errar", pois ao criar o MCS, Romulo Campos Lins afirma:

Eu tinha muitas inquietações e perguntas relacionadas à sala de aula, sempre coisa de professor mesmo, e que os autores que eu lia não me ajudavam a tratar. Em particular, queria dar conta de caracterizar o que os alunos estavam pensando quando "erravam", mas sem recorrer a esta ideia do erro. (LINS, 2012, p.11).

Outro elemento aproximativo do MCS à Etnomatemática, pelo menos a que propomos, dá-se a partir do entendimento de Lins $(1999$, p.92) a respeito de uma Educação Matemática 
praticável:

1. explicitar, na escola, os modos de produção de significado da rua;

2. produzir legitimidade, dentro da escola, para os modos de produção de significado da rua (ato político, ato pedagógico);

3. propor novos modos de produção de significado, que se juntam aos da rua, ao invés de substituí-los. (LINS, 1999, p.92).

O que é realmente relevante é que tradicionalmente a escola negou os significados da rua, e se esforçou em tentar implementar o domínio dos significados da escola; no caso da Matemática, os significados matemáticos (oficiais), e aqui voltamos outra vez a importância de examinarmos pressupostos. (LINS, 1999, p.90).

O MCS é um modelo epistemológico elaborado, que incorpora ideias do pensamento de Vygotsky $(1993,1994)$ e Leontiev $(s d, 1984)$ e não se restringe a uma teoria a ser estudada, mas uma teorização a ser adotada, pois, segundo Lins (2012, p.11) o MCS só existe em ação, que converge com a dinâmica da sistemática do conjunto de ações desenvolvidas pelo professor no ciclo de discussão em grupo, como apresentado anteriormente, advindo de Chaves (2000, p.201).

Ao adotarmos o MCS como procedimento de análise viabiliza-se ampliar espectralmente o entendimento a respeito da maneira de operar dos alunos, sejam eles do ensino básico ou dos processos de formação de professores.

os pressupostos da teoria, pensar em caminhos que apontariam para ações concretas de interação entre professor e aluno e possibilidades de intervenção advindas da leitura da produção de significados desses estudantes (SILVA; LINS, 2013, p.3).

Os elementos relevantes do MCS neste texto são: leitura plausível; significado; conhecimento; autor-texto-leitor; interlocutor; espaço comunicativo; produção de 
significado; legitimidade. No MCS a noção de significado de um objeto é entendida como aquilo que o sujeito pode e efetivamente diz a respeito de um objeto no interior de uma atividade e é no interior de uma atividade que se dá a produção de significado.

Por leitura plausível consideramos "Toda tentativa de se entender um autor deve passar pelo esforço de olhar o mundo com os olhos do autor, de usar os termos que ele usa de uma forma que torne o todo de seu texto plausível" (LINS, 1999, p.93).

Francisco (2008) considera que ao se realizar uma leitura plausível leva-se em consideração a aproximação de "um olhar antropológico que procura conhecer como a cultura de um determinado grupo social funciona, sem a necessidade de alteração ou mudança desse ambiente por julgá-lo menos ou mais importante pelos olhos de quem o estuda". Tal concepção converge com o que já foi exposto anteriormente a respeito das DCN, dos PCN, da LDB e com a enunciação a respeito do direcionamento de uma pesquisa empírica de abordagem etnomatemática, caracterizada

como a investigação das tradições, práticas e concepções matemáticas de um grupo social subordinado (quanto ao volume e composição de capital social, cultural e econômico) e o trabalho pedagógico que se desenvolve com o objetivo de que o grupo interprete e decodifique seu conhecimento; adquira o conhecimento produzido pela Matemática acadêmica, estabeleça comparações entre seu conhecimento e o conhecimento acadêmico, analisando as relações de poder envolvidas no uso destes dois saberes (KNIJNIK, 1996, p.109-110).

Segundo o modelo epistemológico em voga, quem produz uma enunciação é o autor.

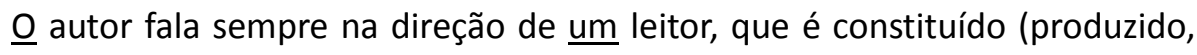
instaurado, instalado, introduzido) pelo $\underline{o}$ autor. Quem produz significado

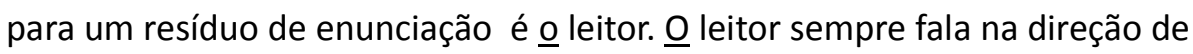

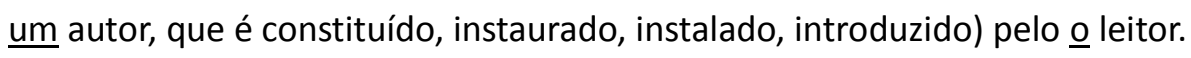




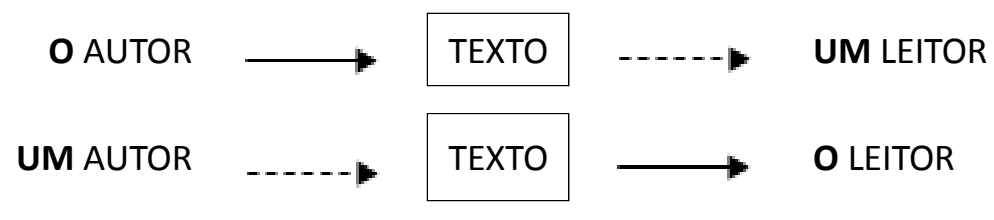

O sujeito cognitivo se encontra com o que acredita ser um resíduo de enunciação, isto é, algo que acredita que foi dito por alguém (um autor). Isto coloca uma demanda de produção de significado para aquele algo, demanda que é atendida (esperançosamente) pela produção de significado de o autor em que se tornou o leitor. $\underline{0}$ autor-leitor fala na direção do um autor que aquele constitui; o um autor é o interlocutor (um ser cognitivo) (LINS, 2012, p.14-15) (ipsis literis).

Logo, um texto é constituído como um resíduo de uma enunciação (LINS, 1999, p.88). Quem fala, o faz em uma direção, a partir de um referencial, que leva em consideração o que pensa e que se constitui como "verdadeiro". A busca de interlocução e os ajustes na efetiva comunicação na relação autor-texto-leitor supracitada, são feitas com o propósito de se constituir um entendimento, portanto, no compartilhamento de um mesmo espaço comunicativo, visto que o papel da justificação é produzir legitimidade para minha enunciação. É importante que entendamos que interlocutor não é um ser biológico, mas cognitivo; é uma direção na qual se fala (LINS, 2012, p.19).

Quando falo na direção de um interlocutor é porque acredito que este interlocutor diria o que estou dizendo e aceitaria/adotaria a justificação que me autoriza a dizer o que estou dizendo. (LINS, 2012, p.19).

Um espaço comunicativo não é algo físico, mas do campo da cognição, visto que este é constituído pelo compartilhamento de interlocutores, pois "toda produção de conhecimento é feita na direção de um interlocutor que, acredito, produziria a mesma enunciação com a mesma justificação." (LINS, 1999, p.88). 
Ao considerarmos os saberes cotidianos como modos não-hegemônicos de matematizar, bem como dinâmicas matemáticas não-legitimadas pela academia e saberes escolares como modos hegemônicos de matematizar, bem como dinâmicas matemáticas legitimadas pela academia, não buscamos estabelecer uma relação dicotômica, ao contrário disto, entendemos que 0 trânsito entre esses saberes possibilita o que denominamos anteriormente como busca de interlocução e os ajustes na efetiva comunicação na relação autor-texto-leitor produzidas com o propósito de se constituir um espaço comunicativo. Dessa forma, entendemos ser possível, a partir de uma leitura plausível, atingir nossas premissas $\left(P_{2}\right),\left(P_{5}\right)$ e $\left(P_{7}\right)$.

Para o MCS conhecimento é uma crença-afirmação associada a uma justificação que nos permite produzir aquela enunciação. Ele é do domínio da enunciação e há sempre um sujeito do conhecimento, que não é do conhecer. Lins $(1999$, p.87) chama atenção ao fato de que toda produção de significado implica produção de conhecimento e que quem produz significado não é o emissor, mas o receptor de uma enunciação. "O significado de algo é aquilo que digo deste algo. Grosso modo, significado, para mim, é o que a coisa é" (LINS, 1999, p.86).

Analisar o trânsito e as inter-relações entre os saberes escolares e os saberes socialmente constituídos - ou como aponta Knijnik (1996), as inter-relações entre a Matemática popular e a Matemática acadêmica - ao levar em consideração a questão da parte diversificada do currículo (apontada no Artigo 26 da LDB), considerando suas características regionais e locais da sociedade, bem como os aspectos relacionados ao mundo físico e natural e da realidade social e política (conforme BRASIL, 1996) possibilita entre aluno e professor, ou leitor e autor, não necessariamente nessa ordem, que se se produza um compartilhamento do mesmo espaço comunicativo, desde que o professor, tal como em $\left(P_{2}\right)$ e $\left(P_{7}\right)$, desempenhe o papel de mediador de uma educação que incorpore uma análise da realidade socioambiental opondose àquela em que o aluno é levado a ignorar as consequências dos seus atos. 
Não se trata, tão-somente, de dar crédito aos resíduos de enunciação do aluno. O que se busca é uma interlocução e, para o MCS o interlocutor (como já dito, ser cognitivo e não biológico) é uma direção na qual se fala.

Quando falo na direção de um interlocutor é porque acredito que este interlocutor diria o que estou dizendo e aceitaria/adotaria a justificação que me autoriza a dizer o que estou dizendo (LINS, 2012, p.19).

Dessa maneira, a partir das premissas apresentadas $\left(\right.$ de $\left(P_{1}\right)$ a $\left.\left(P_{8}\right)\right)$, e na busca de uma interlocução, é possível tomar a Matemática enquanto sistema cultural:

Trata-se de pensá-la não de forma abstrata, imune às lutas do campo simbólico que buscam a manutenção ou ascensão nas posições do espaço social onde ela é produzida e reproduzida. Ao contrário, busco entende-la, enquanto uma das manifestações simbólicas de um determinado grupo social, relacionada com sua posição de dominação ou subordinação no espaço social onde está inserido. Mais ainda, considero que não só a Matemática é uma manifestação simbólica: falar a seu respeito, teorizar sobre ela, interpretá-la, também o é (KNIJNIK, 1996, p.95-96).

Mais do que possível é legítimo; não por uma questão de autoridade, pois como aponta Lins (2012, p.21) "a autoridade não 'explica' nada, ela apenas autoriza, empresta legitimidade" pois,

o que se internaliza não é o conteúdo, não são conceitos, e sim legitimidades: a pessoa já era capaz de fazer; mas não sabia que nesta ou naquela situação aquilo era legítimo, que nesta ou naquela situação aquele modo de produção de significado era legítimo. [...] Internalizar interlocutores, legitimidades, é o que torna possível a produção de conhecimento e significado, torna possível antecipar uma legitimidade do que digo (LINS, 2012, p.20). 


\subsubsection{Outros aportes teóricos}

Chaves (2004 e 2005) propõem o desenvolvimento de Práticas Educativas Investigativas (PEI). Tais obras argumentam que o uso destas práticas não só desestabiliza a inércia mantenedora do ETM, mas também viabiliza que se trabalhe no viés socioambiental e, para tal, destacam o quão importante é que:

(i) pensemos o papel da Matemática nas nossas práticas letivas;

(ii) repensemos nossas práticas (ações docentes, no campo político-filosófico);

(iii) conheçamos o que é e como se processa uma PEI na aula de Matemática e quais as implicações no desenvolvimento dessas práticas.

O cerne destas práticas está em instrumentalizar o aluno para que ele possa agir e intervir em um problema local (agir localmente, mas pensando globalmente), e ao propor tais ações que sejam exaltados valores como a solidariedade e a liberdade, para que o conhecimento se construa a partir de um problema que leva a sistematização de conceitos - as ciências a serviço da comunidade. Assim, ao agir para efetuar intervenções locais objetivamos romper com o ensino excludente e descontextualizado, portanto bancário.

Em uma PEI, a investigação associada ao trabalho - laborial ou intelectual - é uma constante que objetiva estabelecer uma ruptura com os valores de tradições escolares, presentes desde a Grécia Antiga, onde só era possível dedicar-se à atividade do conhecimento se não estivesse escravizado pela obrigação de trabalhar. A própria origem da palavra escola está comprometida com o ócio, que em grego se diz scholé, que deu origem à palavra escola. Na sociedade grega antiga a atividade de produzir uma obra era tão desprezível que não existia a palavra "trabalho". Os vocábulos ergon (em grego) e opus (em latim) referem-se exclusivamente às obras já produzidas.

Quando, por exemplo, um professor demonstra um teorema ou resolve na lousa um 
exercício, é comum observar que todo o seu esforço, de diversas tentativas e de erros, é sonegado para que seja apresentado somente o resultado final, ou o mais trivial. Como se a produção de conhecimento matemático resultasse de atos simples, contínuos; isto é, somente o opus, ou ergon, é valorizado e ao exaltar o opus, ou ergon, desprezando os conflitos e confrontos (os erros) que levam à produção do conhecimento; são mantidas as dicotomias: certo versus errado; quem é inteligente, por saber determinado conceito, e quem não está apto à educação vigente (a manter-se preso ao ETM).

Entendemos por Prática Educativa Investigativa (PEI) aquela que não se restringe ao ambiente da sala de aula, que se constrói através de ambientes e cenários investigativos em que há o compromisso de estimular a curiosidade, a espontaneidade de pensamentos e de ações. Uma PEI por agregar os indivíduos envolvidos no processo em torno da resolução de um problema local, construída a partir das dúvidas e das incertezas que surgem ao longo do processo - na alternância. (CHAVES, 2005, p.128).

Como princípios fundantes de uma PEI, Chaves (2005) destaca:

(1) O princípio da liberdade de expressão - pertinente ao professor; consiste em deixar que o aluno fale, que produza incertezas e que discuta o erro como forma de propiciar a construção de novos aprendizados.

No dia-a-dia de uma EFA isso ocorre quando o alternante leva para casa uma pesquisa de plano de estudo e retorna à EFA com suas constatações, que irão possibilitar a construção de uma alternância e, consequentemente, por tudo que já discutimos, a construção de um rol de atividades e conteúdos programáticos (CHAVES, 2005, p.128).

(2) O princípio da ordem natural (primeiro surge o problema e depois o instrumental para enfrentá-lo) - consiste em permitir que o conteúdo surja a partir da necessidade de se obter respostas à situação que se está investigando. 
(3) O princípio colaborativo - consiste em assinalar o tipo de interferência que o professor realiza nos grupos de trabalho. Sua participação é fundamental na organização do processo, o que não significa que ele deva centralizar informações, nem tampouco que deva passá-las aos alunos como algo pronto e acabado

pois, com este mesmo posicionamento, o professor não perde de vista que não há o caminho, a verdade; mas que existem verdades e caminhos que devem ser discutidos, refletidos e negociados. Desta forma, superamos a clássica relação do aluno passivo (ouvinte) e do professor ativo (dono da palavra, detentor de conhecimentos imutáveis). Em uma PEI, o alternante trabalha com o grupo e o monitor orienta. Nem monitor, nem alternante são donos da verdade. Juntos buscam construir novos conhecimentos (CHAVES, 2005, p.128).

(4) O princípio da integração - consiste em facultar que ocorra uma discussão conjunta com diversas áreas do conhecimento, não se tratando mais de um trabalho exclusivo de certa área do conhecimento: "Não é, por exemplo, a Matemática que está no centro do processo, mas a possibilidade de desestabilizar uma inércia, intervindo localmente" (CHAVES, 2005, p.128). Também faz parte do princípio da integração a organização do espaço, bem como o desenvolvimento de quaisquer tarefas, laboriosas ou não; tarefas estas que são assumidas pelos alunos e orientadas pelos professores. Assim, o professor de Matemática pode experimentar algo novo, deixando aflorar o seu papel também de educador e não somente o de matemático. Com a integração, o foco central não é a Matemática, mas a busca da resolução de um problema presente, em que a Matemática é uma das ferramentas no processo.

Com esse princípio ressalta-se a necessidade de planejamento integrado e contínuo e mais ainda, possibilita que venha a emergir o papel de educador sobrepondo-se ao de técnico. Há também a necessidade de trabalhar trans, multi e interdisciplinarmente. 
As visitas (técnicas e de estudo), as aulas de campo, os ambientes diversos das EFA - fora da sala de aula - ganham uma posição de destaque como ambientes propícios à aprendizagem ou à construção de novos conhecimentos (...) As áreas externas são riquíssimas, por possibilitarem que outros sentidos (além da audição e da visão) sejam envolvidos e utilizados no processo de construção de conhecimentos (tato, paladar, olfato, visão abrangente e audição ampliada). Ecologicamente falando, quanto maior a diversidade do ambiente mais rico ele é. O princípio da integração faculta produzir uma educação ecológica do ponto de vista da diversidade tática e metodológica. Um exemplo que ocorre no cotidiano das EFA se dá, normalmente, no 10 eixo, quando se discute os tipos de cultura existentes na propriedade e constata-se que existem técnicas diferentes de plantio para uma dada cultura ou espécie (por exemplo, a cultura do milho). Não cabe ao monitor afirmar que o espaçamento correto é o adotado na propriedade do alternante " $\mathrm{A}$ " ou " $\mathrm{B}$ "; entretanto, é extremamente educativo discutir os prós e os contras de cada realidade local (para silagem há uma técnica de espaçamento específico e para a produção de grãos outra). Então, a defesa de uma metodologia está associada às características locais. Com isso, o monitor não dá uma "receita" pronta, mas discute e sistematiza possibilidades, porém a escolha final é do agricultor. A construção de cadernos didáticos, com o fichamento de todas essas possibilidades estudadas, é um material de referência rico, tanto para o alternante quanto para sua família e também para a comunidade. Além de tudo, é um registro histórico (CHAVES, 2005, p.128-129).

(5) O princípio da intervenção - é estratégico, consiste em implementar uma PEI voltada para situações locais que envolvam o aluno e o seu habitat (escola, comunidade, família etc.), de tal forma que ele possa utilizar a Matemática como uma ferramenta, um conjunto de técnicas que o possibilite produzir conhecimento que lhe permita intervir nestas situações locais, com o propósito de operar possíveis transformações nos quadros socioambientais apresentados. 
Voltamos à questão balizadora da Pedagogia da Alternância, que é intervir em problemas que envolvam o homem do (no) campo. Somente com a intervenção local poderemos desestabilizar a inércia que mantém os atuais quadros de injustiças e falta de assistência adequada ao campesino, minimizando assim a necessidade de migração (diríamos fuga para os grandes centros urbanos com seus problemas e colapsos sociais). Este princípio está alicerçado nos 3o e 40 pilares das EFA (formação integral do jovem e desenvolvimento do meio). A atividade retorno é um instrumento que pode vir a contribuir para que o alternante desenvolva ações como agente desestabilizador da inércia mantenedora dos problemas do campo (CHAVES, 2005, p.129).

(6) O princípio do dispositivo tático - consiste em desenvolver a produção de conflitos, incertezas e confrontos que propiciem a produção de conhecimento para se contrapor às verdades impostas pela produção de conhecimentos que minimizam, ocultam ou mascaram os problemas típicos das questões socioambientais existentes (aqueles propagados pelo ETM).

Para dinamizar tal princípio, não rechaça o erro e a dúvida; é a partir da incerteza e do erro que se busca construir ou evidenciar conceitos, ideias, propriedades e princípios, pois acredita-se que a luta travada para produzir conhecimento é mais importante do que o próprio conhecimento. Por isso, em uma PEI, se fala em produção de conhecimento, exaltamos a produção de uma obra (o processo de realização do trabalho) e não o trabalho realizado, pronto e acabado. A contínua perseguição à auto-organização, ao autogerenciamento e à autonomia de produtores e comunidades faz parte da meta que as EFA se dispõem a atingir. O princípio tático é um possível referencial para concretizar a etapa de planejamento que ocorre durante o processo de uma alternância. Como esses planejamentos ocorrem nas reuniões administrativas e pedagógicas das equipes, registrar os acertos e erros cometidos facilitarão tanto a sistematização quanto a implementação 
de ações futuras. Na sala de aula o dispositivo tático serve para se repensar o ato de avaliar. No nosso entendimento avaliamos o processo, isto é, o comportamento do aluno desde o início até o final da alternância. O que está em questão é sua maturação e envolvimento diante do tema e não seus erros. É sua produção que deve ser avaliada, jamais sua improdutividade (CHAVES, 2005, p.129).

(7) O princípio da liberdade enquanto fim - como expressão genuína da criatividade e de espontaneidade dos indivíduos no processo de aprendizagem dos conhecimentos tem grande relevância em uma PEl.

A liberdade, somada à criatividade e à espontaneidade de alternantes e monitores, permite que aflore a dinâmica de auto-organização e de autoresponsabilização no processo de aprendizagem dos múltiplos saberes, e estas são pilares que orientam o comportamento dos envolvidos em uma PEI no sentido de aprendizados integrados, opondo-se à fragmentação curricular e também ao enrijecimento de programas e currículos (CHAVES, 2005, p.130).

Tais princípios circulam durante o processo que pode ser representado a partir do seguinte esquema. 
Figura 1. Etapas de uma PEI.

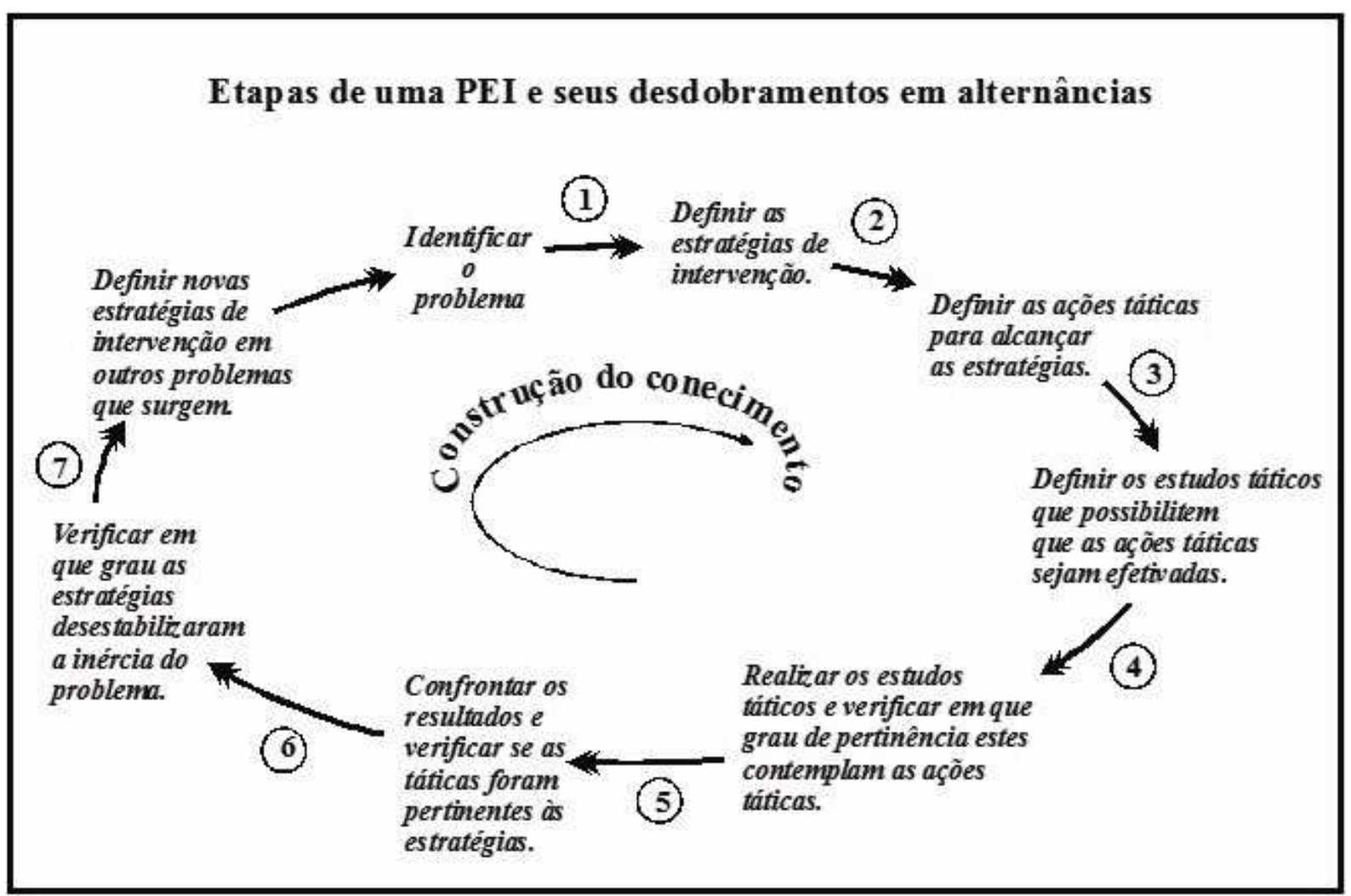

Fonte: Chaves (2005, p.130).

Um fator de ordem prática interessante é que por meio de uma PEI podemos trabalhar com Etnomatemática, Resolução de Problemas ou Modelagem ou Modelação Matemática em um cenário investigativo, na linha de projetos, ou de alternâncias, ou balizado pelos temas geradores. Ao associarmos as etapas de uma PEI com o desenvolvimento de alternâncias devemos destacar que os eixos geradores, os planos de estudo e o plano de formação são elementos que propiciarão a manutenção do ciclo apresentado na figura antecedente. (CHAVES, 2005, p.130) (grifo nosso).

A obra em questão aponta que o trabalho com Matemática, no eixo gerador "o meio socioprofissional", sugere que se inicie a partir de situações-problema intervindo em questões locais, por isso sugere que o alternante (aluno) deva ser colocado diante de um problema para que possa pensar em táticas e estratégias de ação, pois, caso contrário, no 
ano subsequente não conseguirá libertar-se para elaborar um projeto. Desta forma, sugere uma abordagem metodológica pautada em cenários investigativos. Daí a proposta de se trabalhar com PEI.

\section{RESULTADOS E DISCUSSÃO}

A manutenção do mito positivista do especialista impossibilita que se traga à luz da discussão o pensamento etnomatemático (aquele interessado em examinar as práticas de fora da escola), distancia quaisquer possibilidades de se discutir não apenas a política de conhecimento dominante praticada na escola, mas sucumbe qualquer tentativa de trazer para o centro do processo o conhecimento não-hegemônico. Ao contrário, tal rotina só reafirma a política de conhecimento dominante. É básico que se tome o parâmetro de pensar a atividade matemática, no contexto escolar, como dinâmica e, portanto, deve servir à compreensão e transformação da sua realidade, como apresentado em (BRASIL, 1998).

A manutenção desse mito positivista nega os significados da rua, o que está diametralmente oposto do que é considerado como praticável para o MCS. Logo, para negar essa prática, urge que se relacione observações do mundo real - resíduos de enunciação, segundo o MCS - com representações (esquemas, tabelas, figuras, escritas numéricas) - textos, segundo o MCS - como suscitado em Brasil (1998), relacionando estas representações, com princípios e conceitos matemáticos, portanto efetuando leituras plausíveis, a partir do momento que se toma a realidade e o discurso da realidade do aluno, estabelecendo assim um espaço comunicativo entre professor e aluno, tornando a comunicação entre ambos relevantes, para que haja uma interlocução o que só se processará a partir de (P2), levando-se o aluno a 'falar' e a 'escrever' sobre Matemática, a trabalhar com representações gráficas, desenhos, construções, a aprender como organizar e tratar dados.

O problema real, bem como as dinâmicas não-hegemônicas apresentadas pelo aluno, neste processo, passa a ser a força-motriz para que, a partir de (P1), o professor estabeleça com o 
mesmo um espaço comunicativo de forma que o aluno possa produzir significados matemáticos que resultem em possíveis conexões entre sua realidade, a Matemática e as demais áreas.

Quando Knijnik et al (2012) propõe que olhar outras racionalidades, sem se esquecer do que está em voga, é pensar outras possibilidades para a Educação Matemática praticada na escola, entendemos que este olhar nos permite pensar a Etnomatemática, pelo menos como um processo de desestabilização do ETM onde o professor (sua prática e discurso) assumindo (P1) e (P2) efetua o papel de interlocutor intervindo e, portanto, transformando a realidade vigente e considerando, tal como o MCS, a Etnomatemática não como uma teoria, mas como uma ação que possibilita internalizar não conceitos ou conteúdos, mas legitimidade, o que, segundo Lins (2012, p.20), “internalizar interlocutores, legitimidades, é o que torna possível a produção de conhecimento e significado, torna possível antecipar uma legitimidade do que digo".

Para assumirmos um viés entre MCS e Etnomatemática, é importante que se entenda que o mesmo dar-se-á no campo da ação, pois assim emergem leituras plausíveis face à produção de significados matemáticos e a respeito de uma Educação Matemática a ser praticada e, para tal, é fundamental envolver processos de formações de professores, entendemos que a dinâmica apresentada em (P1) será possível a partir da sistemática que tomamos de Chaves (2000, p.201). O que garantirá a confluência no campo da ação é a tomada de (P2) como modelo, pois é (P2) que funciona como amálgama entre ambos.

Chaves (2004 e 2005) propõem o desenvolvimento de PEI como um exercício de contra poder, de desestabilização aos tipos de controle impostos a partir do ETM. Tal obra argumenta que o uso destas práticas não apenas desestabiliza a inércia mantenedora do ETM como também viabiliza que se trabalhe no viés socioambiental, portanto, voltado à realidade do aluno, como posto pelas premissas (P2), (P3), (P4), (P6) e (P7). 


\section{CONSIDERAÇÕES FINAIS}

Observamos que há uma confluência entre o que o MCS toma na trilogia autor-texto-leitor e sujeito escolar, na ótica de Knijnik et al (2012, p.25) (estudante, professor e demais membros da escola, assujeitado, que dá sentido à própria vida e às coisas do mundo, tornando-se o que é): "um sujeito cognitivo que falaria em uma voz singular, única, monoglóssica." (KNIJNIK et al, 2012, p.22). O sujeito escolar, então, segundo tal vertente, passa a ser o interlocutor, a direção na qual se fala, um ser cognitivo, com quem estabelecemos um dialogismo, na ótica de Lins (2012, p.19). A busca de tal interlocução faz sentido para que se viabilize outras formas de matematizar que não as hegemônicas, e daí propor novos modos de produção de significado que adicionem aos da rua, conforme apresenta Lins (1999, p.92), para que se possa negociar a legitimidade dos modos de produção de significado de forma a ter impacto efetivo na vida profissional da pessoa (sujeito escolar).

Entendemos que a partir destes resíduos de enunciação, que por hora, segundo o MCS, configuram-se como texto, será fundamental elaborar um plano, ainda que provisório, para avançarmos para outras etapas da pesquisa. Mesmo que não tenhamos uma ordenação momentânea, quanto à disposição de seções, visualizamos que devemos, com o referencial apresentado e com outros que surgirão - como por exemplo, Ribeiro Domite \& Ferreira (2006) - percorrer mais uma pergunta de pesquisa: De que forma tais resultados, de possíveis diálogos entre MCS e Etnomatemática, impactarão - e como, por quê e em que graus de pertinência - nos processos de formação de professores e, sobretudo, na desestabilização do ETM?

Há de se levar em conta a ideia apresentada em Lins (1999, p.92-94) de que uma proposta de tal envergadura não se restrinja a "uma Educação Matemática que não seja preparação para vida, e sim vida", da mesma forma "uma reflexão que não seja preparação para a ação e sim ação". Para tal, entendemos que um caminho a trilhar à exiguidade dessa proposta é o da sistematização apresentada em Chaves (2000, p. 201), com foco nas ações diferenciais propostas por Baldino \& Carrera de Souza (1997), para que se possa atingir o problema do 
fracasso do ensino de Matemática, apontado Baldino \& Carrera de Souza (1997) e por Chaves (2004), no que se refere à produção de PEI. Entendemos que o uso de PEI, nos moldes propostos, é a liga básica a possíveis diálogos entre Etnomatemática e Modelo dos Campos Semânticos com vistas às propostas de intervenção apresentadas.

\section{PRÓXIMOS PASSOS}

Conforme apresentado anteriormente, a partir deste trabalho três vertentes surgiram: um TCC; um projeto de mestrado e um projeto de pós-doutorado. Por intermédio desses projetos, no viés de $\mathrm{PEI}$, teremos o campo da ação (atividades de campo tomando como base questões socioambientais e formação de professores).

Duas vertentes, na perspectiva da atividade de campo, podem muito contribuir para as buscas almejadas acerca dos diálogos entre práticas hegemônicas e não-hegemônicas de Matemática, a Etnomatemática e o MCS. São elas a etnografia e a pesquisa-ação, no âmbito da proposta de ação diferencial, propiciando a interlocução com os atores do processo, na busca de um levantamento coletivo relativo às questões que eles trazem, principalmente em relação à educação escolar que querem construir junto aos seus grupos culturais.

Para tal sugerimos a dinâmica de ações diferenciais desenvolvidas pelo professor (CHAVES, 2000, p.201) que permitam atingir as premissas (de (P1) a (P8)) propomos/convidamos, pelo viés da pesquisa-ação, a participar do processo os seguintes atores:

(i) envolvidos com o projeto de pós doutorado: membros GEPEMat; licenciandos do curso de Matemática da UFSM; mestrandos e professores do PPGEMeEF; professores das redes de Ensino Básico de Santa Maria;

(ii) envolvidos com o projeto de mestrado: alunos e professores de escola de Teixeira de Freitas, BA, desenvolvendo $\mathrm{PEI}$, a partir do projeto pedagógico da escola, com atividades com os índios Pataxós Hãn-hãn-hae, de Barra Velha, povoado de Arraial D’Ajuda, distrito (iii) envolvidos no TCC: licenciandos do 
LIMAT, participantes das disciplinas de Matemática Aplicada às Ciências da Terra e da Natureza e Tendências de Pesquisa de Educação Matemática.

O propósito é atacarmos os dispositivos de controle do ETM com ações planejadas que visam alcançar objetivos estabelecidos em grupos de pesquisa-ação para produção de PEl ou que leve o grupo/indivíduo a desenvolver determinada tarefa ou a refletir a respeito de sua prática no que tange o tema proposto, de modo que o mesmo possa intervir em sua própria sala de aula, a partir de sua margem natural de liberdade.

Para perseguir o objetivo geral traçamos os seguintes objetivos específicos a serem alcançados:

- Apresentar, discutir e analisar possibilidades de confluências entre o MCS e a Etnomatemática.

- Elencar e discutir processos não-hegemônicos de natureza matemática presentes nas diferentes culturas dos participantes.

- Construir análises dialógicas, reflexivas e críticas que deem subsídios a formulações de práticas pedagógicas (PEI e MDP) - por parte dos envolvidos - que objetivam estabelecer uma proposta de ensino de Matemática que possa contribuir para o fortalecimento de culturas e práticas sociais locais.

- Identificar, analisar e discutir possíveis conflitos culturais causados pelo ensino hegemônico de Matemática tratados pelos atores.

- Promover discussões entre (e com) os atores visando desenvolver coletivamente, em modo intercultural, o espírito de pesquisa - sobretudo de sua própria prática - e assim, potencializar os resultados almejados. 


\section{AGRADECIMENTOS}

Agrademos aos integrantes do Gepemem pela efetiva participação nas rodas de leituras sobre Etnomatemática e MCS, bem como suas intervenções que tanto contribuíram para o amadurecimento deste trabalho.

Agradecemos aos membros do Grupo Sigma-T, da UNESP de Rio Claro, por formarem conosco um espaço comunicativo que nos permitisse produzir leituras plausíveis a respeito do modelo epistemológico em questão.

Agradecemos aos alunos das disciplinas de Tendências de Pesquisa em Educação Matemática e Matemática Aplicada às Ciências da Terra e da Natureza, do LIMAT, pela interlocução e paciência.

\section{REFERÊNCIAS}

BALDINO, R. R.; CARRERA de SOUZA, A. C. Grupo de Pesquisa-Ação em Educação Matemática. Em: Resumo técnico: relatório do sistema diretório dos grupos de pesquisa no Brasil, UNESP, IGCE, Rio Claro: CNPq, 1997. 25 p.

BALMAN, Z. Vida para consumo: a transformação das pessoas em mercadoria. Rio de Janeiro: Zahar, 2008.

BRASIL. Ministério da Educação. Secretaria de Educação Básica. Secretaria de Educação Continuada, Alfabetização, Diversidade e Inclusão. Secretaria de Educação Profissional e Tecnológica. Conselho Nacional da Educação. Câmara Nacional de Educação Básica. Diretoria de Currículos e Educação Integral. Diretrizes Curriculares Nacionais Gerais da Educação Básica. Brasília: MEC, SEB, DICEI, 2013. 565p.

BRASIL, Ministério da Educação e do Desporto, Instituto Nacional de Estudos e Pesquisas Educacionais. Parâmetros Curriculares Nacionais para o Ensino Fundamental: introdução. Brasília, 1998. 174 p.

BRASIL, LDB. Lei 9394/96 - Lei de Diretrizes e Bases da Educação Nacional. Disponível em $<w w w . p l a n a l t o . g o v . b r>$. Acesso em: 25 abr. 2015.

CHAVES, R. Material pedagógico na base nacional comum na linha da pedagogia da 
alternância: ensino de Matemática nas Escolas Família-Agrícolas. Viçosa, MG: Departamento de Educação da UFV, Associação das Escolas Família-Agrícolas de MG, 2005.

- Por que anarquizar o ensino de Matemática intervindo em questões socioambientais? Tese (Doutorado em Educação Matemática). Programa de Pós-Graduação em Educação Matemática, Instituto de Geociências e Ciências Exatas de Rio Claro. Universidade Estadual Paulista, 2004.

. Caminhos percorridos para a implantação do grupo de pesquisa-ação em educação matemática junto ao núcleo de ensino integrado de ciências e matemática da Universidade Federal de Viçosa. (Dissertação de Mestrado em Educação Matemática). Programa de PósGraduação em Educação Matemática, Instituto de Geociências e Ciências Exatas de Rio Claro. Universidade Estadual Paulista, 2000.

D'AMBROSIO, U. Um enfoque antropológico da matemática e do ensino. Em: FERREIRA, M. K. L. Ideias matemáticas de povos culturalmente distintos. São Paulo: 2002. p. 25-36.

Etnomatemática: Elo entre as Tradições e a Modernidade. Belo Horizonte: Autêntica, 2001.

A História da Matemática: Questões Historiográficas e Políticas e Reflexos na Educação Matemática. Em: BICUDO, Maria A. V. (Org.). Pesquisa em Educação Matemática: Concepções \& Perspectivas (Seminários \& Debates). São Paulo: Editora UNESP, 1999, p. $97-$ 115.

- Educação Matemática: da Teoria à Prática. Perspectivas em Educação Matemática/SBEM. Campinas: Papiros, 1996.

Etnomatemática. São Paulo: Ática, 1990.

DANTAS, S. C.; CYRINO, M. C. da C. O Modelo dos Campos Semânticos como estratégia de análise de uma investigação. Em: ANGELO et al (org.). Modelo dos Campos Semânticos e Educação Matemática: 20 anos de história. São Paulo: Midiograf, 2012.

FERREIRA, E. S. Etnomatemática: Uma Proposta Metodológica. Rio de Janeiro: MEM/USU, 1997. (Série Reflexão em Educação Matemática).

FRANCISCO, C. A. O Modelo dos Campos Semânticos como Instrumento de Leitura da Prática Profissional do Professor de Matemática. Disponível em: <http://www2.rc.unesp.br/eventos/matematica/ebrapem2008/upload/306-1-Agt1_francisco_ta.pdf>. Acesso em: 21 mar. 2015.

GIL, A. C. Como elaborar projetos de pesquisa. 5. Ed. São Paulo: Atlas, 2010.

KNIJNIK, G.; WANDERER, F.; GIONCO, I. M.; DUARTE, C. G. Etnomatemática em movimento. Coleção Tendências em Educação Matemática. Belo Horizonte: Autêntica, 2012. 
KNIJNIK, G. Exclusão e Resistência: Educação Matemática e legitimidade cultural. Porto Alegre: Artes Médicas, 1996.

Leontiev A. N. O Desenvolvimento do psiquismo. São Paulo: Moraes, (sd). . Actividad, conciencia y personalidade. México: Cartago, 1984.

LINS, R. C. O Modelo dos Campos Semânticos: estabelecimento e notas de teorizações. Em: ANGELO et al (org.). Modelo dos Campos Semânticos e Educação Matemática: 20 anos de história. São Paulo: Midiograf, 2012.

. Por que discutir teoria do conhecimento é relevante para a Educação Matemática. Em: BICUDO, Maria Aparecida Viggiani (org.). Pesquisa em Educação Matemática: concepções \& perspectivas. Seminários DEBATES Unesp. São Paulo: Editora UNESP, 1999.

. Epistemologia, história e educação matemática: tornando mais sólidas as bases da pesquisa. Revista de Educação Matemática da SBEM, São Paulo, n. 1, p.75-91, set/1993.

MONTEIRO, Alexandrina. A Etnomatemática em cenários de escolarização: alguns elementos de reflexão. Em: KNIJNIK, Gelsa; WANDERER, Fernanda; OLIVEIRA, Cláudio José de (org.). Etnomatemática: currículo e formação de professores. Santa Cruz do Sul: EDUNISC, 2004. p. 432-446.

SILVA, A. M.; LINS, R. C. Sobre a dinâmica da produção de significados para a matemática. Jornal Internacional de Estudos em Educação Matemática. 1, v.6 (2), 2013. Disponível em: $<$ http://periodicos.uniban.br/index.php?

journal=JIEEM \&page=article\&op=view\&path[0]=373\&path[1]=395>. Acesso em 15 dez. 2014.

Vygotsky, L. S. A formação social da mente. 5.ed. São Paulo: Martins Fontes, 1994.

Pensamento e linguagem. São Paulo: Martins Fontes, 1993. 